\title{
Correction to: Lipoic acid nanoforms based on phosphatidylcholine: production and characteristics
}

\author{
V. A. Shchelkonogov ${ }^{1,4}$ - S. O. Alyaseva ${ }^{1}$. N. Yu. Lotosh ${ }^{2}$ - O. A. Baranova ${ }^{4}$ A. V. Chekanov ${ }^{4}$ (1) $\cdot$ E. Yu. Solov'eva ${ }^{4}$. \\ R. A. Kamyshinskii ${ }^{2}$ R. G. Vasilov ${ }^{2}$ N. S. Shastina' - E. A. Korepanova ${ }^{4,5}$ - A. A. Anosov ${ }^{5}$. A. A. Selishcheva ${ }^{2,3,4}$
}

Published online: 22 September 2021

(c) European Biophysical Societies' Association 2021

\section{Correction to: \\ European Biophysics Journal (2020) 49:95-103 \\ https://doi.org/10.1007/s00249-019-01415-x}

In the original publication of the article, the family name of the first author was incorrectly spelled. The correct name should be "Shchelkonogov".

The original article has been corrected.

Publisher's Note Springer Nature remains neutral with regard to jurisdictional claims in published maps and institutional affiliations.

The original article can be found online at https://doi.org/10.1007/ s00249-019-01415-x.

A. V. Chekanov avchekanov@mail.ru

1 MIREA-Russian Technological University, Moscow 119571, Russia

2 National Research Center Kurchatov Institute, Moscow 123182, Russia

3 Department of Biology, Lomonosov Moscow State University, Moscow 119234, Russia

4 Pirogov Russian National Research Medical University, Russian Ministry of Public Health, Moscow 117997, Russia

5 Sechenov First Moscow State Medical University (Sechenov University), Moscow 119991, Russia 